\title{
Antibacterial Activity with Bacterial Growth Kinetics and GC-MS Studies on Leaf and Tuber Extracts of Arisaema tortuosum (Wall.) Schott
}

\author{
Kamal Kant ${ }^{1}$, Uma Ranjan Lal ${ }^{2}$, Manik Ghosh ${ }^{1, *}$ \\ 1Department of Pharmaceutical Sciences and Technology, Birla Institute of Technology, Mesra, Ranchi, Jharkhand, INDIA. \\ ${ }^{2}$ School of Pharmaceutical Sciences, Shoolini University, Solan, Himachal Pradesh, INDIA.
}

\begin{abstract}
Background: Pathogenic bacteria (Gram positive/Gram negative) are serving as a vital precursor for the development of infectious diseases in humans. Arisaema tortuosum (Wall.) Schott (ATWS), a famous folklore medicine of Asian region has documented for great medicinal values. Objective: To evaluate the ATWS extracts and their fractions (leaf and tuber part) for antibacterial potential against human pathogens and to probably examine the phytochemicals existing in promising extracts via gas chromatographymass spectroscopy (GC-MS). Methods: The dried young leaves and tubers of ATWS was extracted using $\mathrm{C}_{2} \mathrm{H}_{5} \mathrm{OH}: \mathrm{H}_{2} \mathrm{O}(95: 5, \mathrm{v} / \mathrm{v})$ and further fractionated with $\mathrm{n}$-hexane, chloroform, ethyl acetate and butanol, respectively. The antibacterial activity was carried out using agar well diffusion method. Furthermore, the antibacterial kinetic curve of capable extracts/fractions was too studied using time killing assay. Results: Overall, leaves extracts exhibited greater and varying level of Minimum Inhibitory Concentration (MIC)/ Zone of Inhibition (ZOI) against tested bacterial strains: Staphylococcus aureus (Sa), Bacillus subtilis (Bs), Escherichia coli (Ec) and Salmonella typhimurium (St). Additionally, extracts (Ethanolic for St and Bs, n-hexane for Sa and chloroform for Ec) have mostly inhibited the growth of test organisms for approximate $24 \mathrm{hr}$. The common tentative compounds like phytol, neophytadiene, octadecane, hexahydrofarnesyl acetone etc. were confirmed qualitatively by GC-MS. Conclusion: The antibacterial finding reveals that the leaves of ATWS have considerable antibacterial activity might be due to the presence of various chemical constituents. The tentative compounds confirmed by GCMS from different extracts may further act as a valuable tool for future researchers against various bacterial illnesses.
\end{abstract}

Key words: Arisaema tortuosum, Leaf, Tuber, Extracts, Antibacterial activity, GC-MS analysis.

\section{INTRODUCTION}

As per WHO guideline, bacteria related infections are serving as vital parameters for the development of large mortality rate in under developing countries. Bacterial contaminations are a noteworthy reason for disorder and passing around the world. The purpose behind it is that a large portion of the pathogens causing enteric infections have created protection from generally utilized medications. Protection of microscopic organisms to anti-microbial expands mortality and extends the stay of patients in doctor's facilities. ${ }^{1}$ Addressing the given issue, antimicrobials are especially a concern with negative consequences that incorporate unfavourably hypersensitive responses, repression of the immune system and making the host extremely allergic. Along these lines, it is expected to grow new, more secure, best therapeutic and less expensive anti-infection agents for the treatment of irresistible ailments through herbal remedies. The accomplishment of current medications lies in proceeds with a hunt of new
Submission Date: 27-09-2018; Revision Date: 05-01-2019; Accepted Date: 22-04-2019

DOI: 10.5530/ijper.53.3s.98 Correspondence: Dr. Manik Ghosh, Department of Pharmaceutical Sciences and Technology, Birla Institute of Technology, Mesra, Ranchi- 835215, Jharkhand, INDIA. Phone: +916512276247 E-mail: manik@bitmesra. ac.in

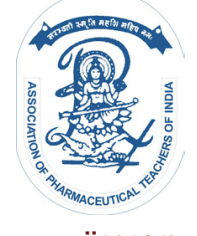

www.ijper.org 
medications. ${ }^{2}$ Nature has been as a wellspring of therapeutic agents since ancient times and a great number of present-day medications have been identified from an herbal origin. Globally, numerous herbs have been operated as a promising medicine in day to day life to treat illnesses. ${ }^{3}$ Arisaema tortuosum (Wall.) Schott (ATWS) commonly known as whipcord cobra lily belonging to plant family Araceae, that has a particular purple or green whip-like spadix, which emerges from the orifice of flower (Jack-in-the-platform) and approximate $30 \mathrm{~cm}$ long. ${ }^{4}$ The plant occurrence is ranging from Himalayan forest, China, Myanmar and Southern Indian parts. ${ }^{5-6}$ Traditionally, a recent report has highlighted that ATWS tuber part claimed for antirheumatic, antiasthmatic, antimicrobial and contraceptive actions. Leaves answered to be reasonably noxious and can be valuable against rheumatism and stomach issue. ${ }^{7}$ Chemical investigation showed that tuber (Corm) has shown distinctive chemical entities like lectin, n-alkanols, stigmasterol, sitosterol, campesterol, cholesterol, choline chloride and stachhydrine hydrochloride, correspondingly. ${ }^{8}$ A study in tuber part of ATWS affirmed the presence of flavonoids and prominent role in antioxidant, anti-inflammatory and anticancer applications. ${ }^{9}$ Out of the constituents, a lectin resulted as principle pro-inflammatory entity and hopeful inhibitor for the human uncontrolled division of cells. ${ }^{10}$ Previously, lectins have presented the role in host-pathogen interaction and also the cytotoxic effects on micro-organisms and parasites. ${ }^{11}$ To the best of our knowledge, mostly tuber part of ATWS was explored for the therapeutic purpose and even leaf part studies were too quite limited. ${ }^{12}$ Therefore, an attempt was made to screen the promising ATWS antibacterial leaf and tuber extracts and further analyze these extracts for the tentative confirmation of chemical constituents using GC-MS.

\section{MATERIALS AND METHODS}

\section{Materials}

The whole plant was gathered near to Mandi district, Himachal Pradesh, India in August-September 2013 and authenticated in-house by a CSIR-NISCAIR, New Delhi taxonomist (Reference Number: NISCAIR/RHMD/ Consult/2013/2249/30). Mueller-Hinton (MH) and Mueller-Hinton Agar (MHA) medium were purchased from HiMedia Laboratories. The bacterial strains ( $\mathrm{Sa}$ 11949, Bs 441, Ec 1687 and St 8767), used for culturing were acquired from IMTECH, CSIR laboratory Chandigarh, India and preserved in our aseptic microbiology lab. Resazurin dye was acquired from Sigma-Aldrich Chemie. Supplementary solvents and chemicals were of analytical mark procured from SDFCL, Mumbai, India.

\section{Methods}

The leaf and tuber parts of ATWS was cleaned, shade dried, grounded to powder (Coarse) properly. A $250 \mathrm{~g}$ of each powdered materials were extracted with ethanol $(95: 5, \mathrm{v} / \mathrm{v})$ and further fractionated with n-hexane, chloroform, ethyl acetate, butanol and other remained as an aqueous extract. These concentrates were lyophilized and reserved in the dark $\left(+3^{\circ} \mathrm{C}\right.$ to $\left.+4^{\circ} \mathrm{C}\right)$ until further use.

\section{Evaluation of Antibacterial Studies}

The culture turbidity of bacteria used for studies was in tune to $0.5 \mathrm{McF}$ arland equivalence prior to use. ${ }^{13}$ Stock solutions of standard ciprofloxacin $(0.1 \mathrm{mg} / \mathrm{mL})$ and extracts $(20 \mathrm{mg} / \mathrm{mL})$ used for the study were dissolved in $5 \%$ DMSO solutions.

\section{Agar well diffusion assay}

All bacterial strains were developed on Müeller Hinton Agar (MHA) (HiMedia Laboratories Pvt. Ltd., Mumbai, India) for $24 \mathrm{hr}$ prior to the experiment. The test cultures computing $50 \mu \mathrm{l}$ were scrubbed/Petri dish of molten Müeller Hinton Agar (MHA) by using an aseptic cotton swab. Wells were prepared using a cork borer (10 $\mathrm{mm}$ diameter), filled with the extracts/ciprofloxacin solution $(20 \mathrm{mg} / \mathrm{mL} / 1 \mathrm{mg} / \mathrm{mL})$ followed by incubation at $37^{\circ} \mathrm{C}$ for $24 \mathrm{hr}$. In addition, the blank (5\% DMSO) was too examined against the tested bacterial strains. ${ }^{14}$

\section{Minimum Inhibitory Concentration (MIC) determination}

A minor revision to broth micro dilution bioassay was done for calculating MIC value. ${ }^{15}$ In brief, resazurin tablet $(270 \mathrm{mg}$ ) was suspended in sterile distilled water (40 $\mathrm{mL}$ ), followed by swirling in order to guarantee a welldissolved and homogenous solution. Additionally, $50 \mu \mathrm{L}$ of extracts and standard $(20 \mathrm{mg} / \mathrm{mL} / 1 \mathrm{mg} / \mathrm{mL})$ were added into multi-well microplate reader holding $50 \mu \mathrm{L}$ of Muller-Hinton broth, $5 \mu \mathrm{L}$ bacterial cultures and 5 $\mu \mathrm{L}$ resazurin, respectively. Resazurin dye pink color positively correlates with bacterial growth. The microplate was clogged with a lid and incubated for $24 \mathrm{hr}$ at $37^{\circ} \mathrm{C}$.

\section{Bacterial growth kinetics}

Bacterial growth period with test extracts was determined by measuring the $\mathrm{OD}_{625}$ in ELISA microplate reader (BiotekEL x 800) and further bacterial inhibition rate was analyzed up to $48 \mathrm{hr}^{16}$

\section{GC-MS analysis}

The separating course of action was carried out using GC-MS (QP2010S; Shimadzu, Kyoto, Japan). Around $0.1000 \% \mathrm{ppm}$ solution of promising antibacterial extracts was prepared and $0.001 \mathrm{~mL}$ of individual 
extract was inserted using Rxi-5Sil MS column. Helium gas was utilized as a carrier gas with a flow rate of 1 $\mathrm{mL} / \mathrm{min}$. The ion source of capacity $250^{\circ} \mathrm{C}$ with ionization energy $70 \mathrm{eV}$ was used. Confirmation was done by comparing mass spectra of analyzed components with reference mass spectra of NIST 11 and Willey 8 library. ${ }^{17,18}$

\section{Statistical Analysis}

The results were manifested as the triplicate measurements of Mean \pm Standard Deviation (SD) against tested bacterial strains.

\section{RESULTS}

The in-vitro antibacterial potential of ATWS extracts was tested by ZOI and MIC studies. The MIC (Leaves and tubers extracts) ranged from $78.13 \times 10^{-3}$ to $2500 \times 10^{-3}$ $\mathrm{mg} / \mathrm{mL}$ while the ZOI ranged between 7.00 to 11.00 $\mathrm{mm}$ and the results are summarized in Table 1. The promising leaf antibacterial extract/fractions of ATWS (Ethanol, n-hexane and chloroform) were studied for bacterial kinetic growth patterns for a period up to $48 \mathrm{hr}$. Figure 1 depicts the time-dependent inhibitory effect of capable ATWS extracts against four foodborne microorganisms (Bs, Ec, Sa and St). Overall, ethanol leaf extract inhibited the maximum growth of $B s$ and $S t$ for approximate $24 \mathrm{hr}$ compared with other extracts. Additionally, n-hexane leaf fraction showed inhibition in growth for $S a$ while chloroform (Leaf fraction) confirmed slow down the growth against $E c$ over $24 \mathrm{hr}$ (Figure 1). Furthermore, the noteworthy plant extracts (Ethanolic, n-hexane and chloroform)

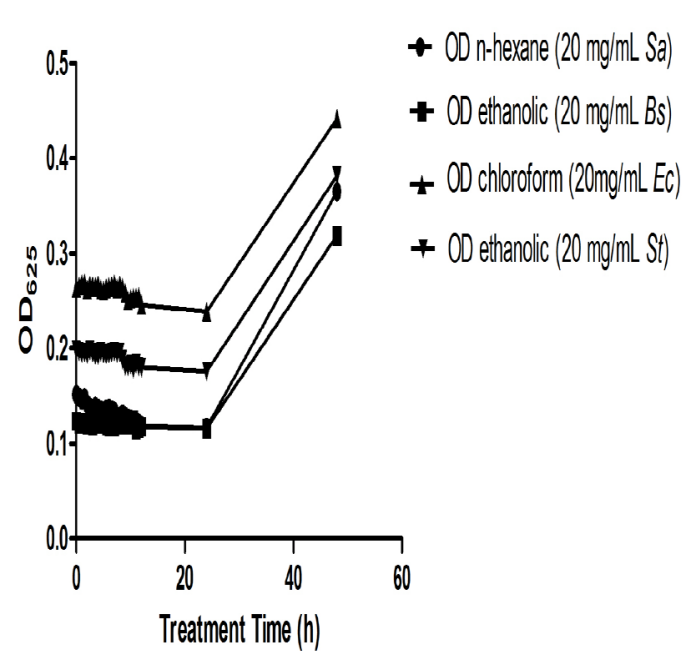

Figure 1: The Time-Dependent Inhibitory Effect of ATWS Extracts/Fractions (Ethanolic, $n$-hexane and Chloroform) against B. subtilis, E. coli, S. aureus and S. typhimurium. were analyzed by GC-MS. The presence of chemical entities was affirmed by noting the similarity of tested components with standard mass spectra of NIST and Willey library. In the GC-MS investigation of ATWS, sixteen compounds were confirmed in ethanolic leaf extract, twenty-one compounds in $\mathrm{n}$-hexane fraction while twenty seven in chloroform fraction. The active chemical entities with their R. Time (RT), Area, Area \%, Height, Height $\%$, name and Base ion $\mathrm{m} / \mathrm{z}$ in ethanolic, $\mathrm{n}$-hexane and chloroform extracts of ATWS are summarized in Table 2, Table 3 and Table 4, respectively. Chromatogram of ethanolic, $\mathrm{n}$-hexane and chloroform extracts are presented in Figure 2 (a, b, c). The chief chemical entities which indicated in ethanolic extract are phenol, 2,4-bis(1,1-dimethylethyl)- (6.93\%), 3-heptadecanol $(0.56 \%)$, pentadecanoic acid, methyl ester $(0.58 \%)$, neophytadiene (0.94), hexahydrofarnesyl acetone $(1.11 \%)$, methyl hexadec-9-enoate $(1.69 \%)$, hexadecanoic acid, methyl ester (19.48\%), 9,12-octadecadienoic acid, methyl ester (20.70\%), 9,12,15-octadecatrienoic acid, methyl ester, (z,z,z)- (37.96\%), cis-13-octadecenoic acid, methyl ester $(1.10 \%)$, phytol $(3.27 \%)$, hexadecane, 2,6,10,14-tetramethyl-(0.60\%), methyl stearate $(2.95 \%)$, octadecane, 1-chloro- $(0.56 \%)$, docosanoic acid, methyl ester $(1.00 \%)$ and tetracosanoic acid, methyl ester $(0.56 \%)$. In $\mathrm{n}$-hexane fraction, twenty one compounds are 2,4-ditert-butylphenol (5.69\%), hexadecan (1.76\%), octadecane $(5.25 \%)$, hexahydrofarnesyl acetone $(7.80 \%)$, cyclopropanenonanoic acid, 2-[(2-butylcyclopropyl) methyl]-, methyl ester (1.05\%), hexadecanoic acid, ethyl ester (13.71\%), 9,12-octadecadienoic acid, methyl ester (1.60\%), 9,12,15-octadecatrienoic acid, methyl ester,

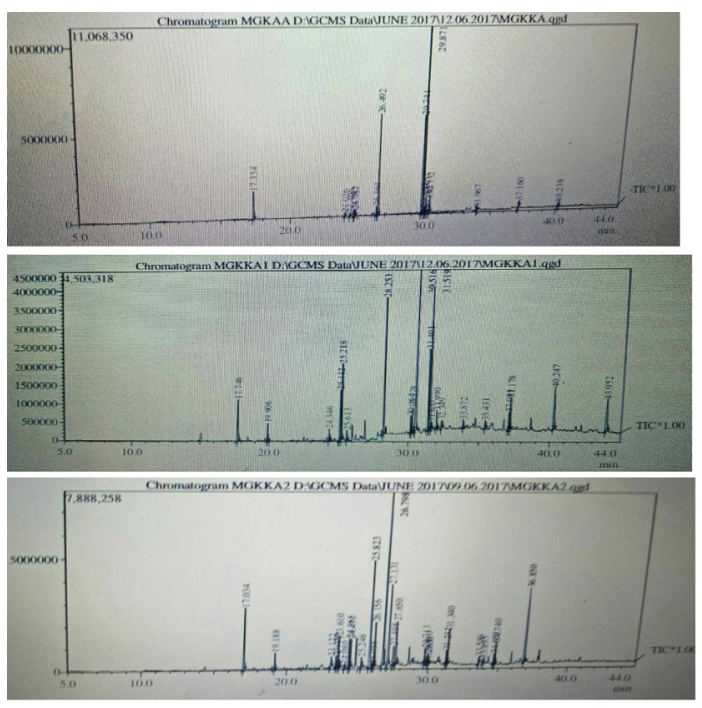

Figure 2: a): Chromatogram of ATWS a) ethanolic extract b): Chromatogram of ATWS b) n-hexane fraction c): Chromatogram of ATWS c) chloroform fraction. 
Table 1: Minimum inhibitory concentration and zone of inhibition of ATWS extracts for tested bacterial strains. Plant Materials MIC (mg/ml)/Zone of Inhibition (diameter in $\mathbf{m m}$ )

\begin{tabular}{|c|c|c|c|c|}
\hline & Sa & Bs & Ec & St \\
\hline A & $312.5 \times 10^{-3} / 7 \pm 0.3$ & $1250 \times 10^{-3} / 11 \pm 0.7$ & $2500 \times 10^{-3} / 7 \pm 0.3$ & $1250 \times 10^{-3} / 11 \pm 0.4$ \\
\hline B & $2500 \times 10^{-3} / 6 \pm 0.6$ & $2500 \times 10^{-3} / 6 \pm 0.8$ & $2500 \times 10^{-3} / 6 \pm 0.8$ & $1250 \times 10^{-3} / 5 \pm 0.2$ \\
\hline A1 & $78.13 \times 10^{-3} / 9 \pm 0.4$ & $2500 \times 10^{-3} / 10 \pm 0.9$ & $2500 \times 10^{-3} / 10 \pm 0.3$ & $2500 \times 10^{-3} / 10 \pm 0.7$ \\
\hline B1 & $156.25 \times 10^{-3} / 8 \pm 0.5$ & $2500 \times 10^{-3} / 9 \pm 0.3$ & $1250 \times 10^{-3} / 5 \pm 0.3$ & $1250 \times 10^{-3} / 6 \pm 0.3$ \\
\hline A2 & $156.25 \times 10^{-3} / 7 \pm 0.6$ & $2500 \times 10^{-3} / 10 \pm 0.4$ & $2500 \times 10^{-3} / 11 \pm 0.8$ & $1250 \times 10^{-3} / 9 \pm 0.4$ \\
\hline B2 & $312.5 \times 10^{-3} / 5 \pm 0.3$ & $2500 \times 10^{-3} / 8 \pm 0.4$ & $1250 \times 10^{-3} / 8 \pm 0.4$ & $1250 \times 10^{-3} / 6 \pm 0.3$ \\
\hline A3 & $78.13 \times 10^{-3} / 5 \pm 0.3$ & $1250 \times 10^{-3} / 7 \pm 0.8$ & $1250 \times 10^{-3} / 6 \pm 0.2$ & $1250 \times 10^{-3} / 9 \pm 0.5$ \\
\hline B3 & $78.13 \times 10^{-3} / 5 \pm 0.5$ & $1250 \times 10^{-3} / 6 \pm 0.4$ & $1250 \times 10^{-3} / 5 \pm 0.1$ & $1250 \times 10^{-3} / 7 \pm 0.3$ \\
\hline A4 & $1250 \times 10^{-3} / 5 \pm 0.3$ & $2500 \times 10^{-3} / 6 \pm 0.8$ & $1250 \times 10^{-3} / 5 \pm 0.3$ & $2500 \times 10^{-3} /-$ \\
\hline B4 & $2500 \times 10^{-3} / 5 \pm 0.4$ & $2500 \times 10^{-3} / 5 \pm 0.6$ & $1250 \times 10^{-3} / 5 \pm 0.7$ & $2500 \times 10^{-3} /-$ \\
\hline A5 & $2500 \times 10^{-3} / 5 \pm 0.1$ & $2500 \times 10^{-3} / 5 \pm 0.2$ & $2500 \times 10^{-3} / 5 \pm 0.3$ & $5000 \times 10^{-3} /-$ \\
\hline B5 & $2500 \times 10^{-3} / 5 \pm 0.4$ & $2500 \times 10^{-3} / 5 \pm 0.3$ & $2500 \times 10^{-3} / 5 \pm 0.7$ & $2500 \times 10^{-3} /-$ \\
\hline S & $0.78 \times 10^{-3} / 27 \pm 0.3$ & $1.56 \times 10^{-3} / 23 \pm 0.2$ & $6.25 \times 10^{-3} / 29 \pm 0.4$ & $0.09 \times 10^{-3} / 25 \pm 0.3$ \\
\hline
\end{tabular}

A/B-ethanolic extract (leaves/tubers), A1/B1-hexane extract (leaves/tubers), A2/B2-chloroform extract (leaves/tubers), A3/B3-ethyl acetate extract (leaves/ tubers), A4/B4-butanolic extract (leaves/tubers), A5/B5-aqueous extract (leaves/tubers), S-standard (ciprofloxacin), Sa-Staphylococcus aureus, BsBacillus subtilis, Ec-Escherichia coli, St-Salmonella typhimurium; Zone of inhibition: used concentration of extracts/standard-20/0.1 mg/ml. Each value is expressed as mean $\pm S D$

\begin{tabular}{|c|c|c|c|c|c|c|}
\hline R. Time & Area & Area\% & Height & Height $\%$ & Name & Base $\mathrm{m} / \mathrm{z}$ \\
\hline 17.334 & 6716331 & 6.93 & 1670893 & 5.71 & Phenol, 2,4-Bis(1,1-dimethylethyl)- & 191.20 \\
\hline 24.026 & 547481 & 0.56 & 193571 & 0.66 & 3-Heptadecanol & 59.10 \\
\hline 24.406 & 564046 & 0.58 & 182908 & 0.62 & Pentadecanoic acid, Methyl ester & 74.10 \\
\hline 24.682 & 912938 & 0.94 & 310697 & 1.06 & Neophytadiene & 68.10 \\
\hline 24.787 & 1074728 & 1.11 & 355874 & 1.22 & Hexahydrofarnesyl acetone & 58.05 \\
\hline 26.364 & 1641133 & 1.69 & 523825 & 1.79 & Methyl hexadec-9-enoate & 55.05 \\
\hline 26.492 & 18894249 & 19.48 & 6021238 & 20.57 & Hexadecanoic acid, Methyl ester & 74.10 \\
\hline 29.741 & 20072235 & 20.70 & 5894362 & 20.14 & 9,12-Octadecadienoic acid, Methyl ester & 67.10 \\
\hline 29.871 & 36805957 & 37.96 & 10986375 & 37.53 & $\begin{array}{c}\text { 9,12,15-Octadecatrienoic acid, Methyl ester, } \\
(\mathrm{z}, \mathrm{z}, \mathrm{z})^{-}-\end{array}$ & 79.10 \\
\hline 29.954 & 1070929 & 1.10 & 334764 & 1.14 & Cis-13-octadecenoic acid, Methyl ester & 55.05 \\
\hline 30.051 & 3167313 & 3.27 & 970896 & 3.32 & Phytol & 71.10 \\
\hline 30.242 & 579115 & 0.60 & 144922 & 0.50 & Hexadecane, 2,6,10,14-tetramethyl- & 57.10 \\
\hline 30.332 & 2859063 & 2.95 & 1007501 & 3.44 & Methyl stearate & 74.05 \\
\hline 33.967 & 544722 & 0.56 & 118980 & 0.41 & Octadecane, 1-chloro- & 57.10 \\
\hline 37.160 & 973982 & 1.00 & 363648 & 1.24 & Docosanoic acid, Methyl ester & 74.05 \\
\hline 40.238 & 547020 & 0.56 & 192723 & 0.66 & Tetracosanoic acid, Methyl ester & 74.10 \\
\hline
\end{tabular}

(z,z,z)- (2.54\%), phytol (16.15\%), ethyl 9,12-hexadecadienoate $(8.35 \%)$, ethyl $(9 z, 12 z)-9,12$-octadecadienoate (14.50\%), 9-octadecenoic acid (z)-, ethyl ester $(0.70 \%)$, octadecanoic acid, ethyl ester $(1.83 \%)$, phytol, acetate $(0.82 \%)$, heptacosane $(0.77 \%)$, ethyl nonadecanoate $(0.74 \%)$, 1-octadecanol $(1.82 \%)$, eicosane $(3.24 \%)$, tetracosylheptafluorobutyrate $(5.07 \%)$ and 1-heptacosanol $(5.46 \%)$. Twenty seven compounds (chloroform) which are indicated by GC-MS are phenol, 2,4-bis(1,1dimethylethyl)- (8.68\%), hexadecane (1.86\%), (-)-loliolide $(1.49 \%)$, e-15-heptadecenal $(1.15 \%)$, nonadecane (2.98\%), 3-heptadecanol $(0.94 \%)$, isopropyl myristate $(0.37 \%)$, neophytadiene $(2.86 \%)$, hexahydrofarnesyl acetone $(2.74 \%)$, phytol, acetate $(1.17 \%), 1,2$-benzenedicarboxylic acid, bis (2-methylpropyl) ester (13.11\%), tetrapentacontane, 1,54-dibromo- $(0.35 \%)$, phthalic 
Table 3: Chemical Entities Detected in ATWS $n$-hexane Fraction.

\begin{tabular}{|c|c|c|c|c|c|c|}
\hline R. Time & Area & Area $\%$ & Height & Height $\%$ & Name & Base $\mathrm{m} / \mathrm{z}$ \\
\hline 17.746 & 4768387 & 5.69 & 1115745 & 4.50 & 2,4-Ditert-butylphenol & 191.15 \\
\hline 19.906 & 1476398 & 1.76 & 472240 & 1.90 & Hexadecan & 57.10 \\
\hline 24.346 & 954965 & 1.14 & 315176 & 1.27 & Octadecane & 57.05 \\
\hline 25.112 & 4404683 & 5.25 & 1337043 & 5.39 & Neophytadiene & 68.10 \\
\hline 25.218 & 6539733 & 7.80 & 2034021 & 8.20 & Hexahydrofarnesyl acetone & 58.05 \\
\hline 25.613 & 878438 & 1.05 & 262524 & 1.06 & $\begin{array}{c}\text { Cyclopropanenonanoic acid, } \\
\text { 2-[(2-Butylcyclopropyl)methyl]-, Methyl ester }\end{array}$ & 149.10 \\
\hline 28.253 & 11491970 & 13.71 & 3622566 & 14.60 & Hexadecanoic acid, Ethyl ester & 88.10 \\
\hline 30.164 & 1343093 & 1.60 & 441804 & 1.78 & 9,12-Octadecadienoic acid, methyl ester & 67.05 \\
\hline 30.278 & 2130909 & 2.54 & 654523 & 2.64 & $\begin{array}{c}9,12,15-\text { Octadecatrienoic acid, Methyl ester, } \\
(z, z, z)-\end{array}$ & 79.10 \\
\hline 30.516 & 13534814 & 16.15 & 4194714 & 16.90 & Phytol & 71.10 \\
\hline 31.401 & 7001340 & 8.35 & 2138446 & 8.62 & Ethyl 9,12-hexadecadienoate & 67.10 \\
\hline 31.519 & 12154625 & 14.50 & 3714895 & 14.97 & Ethyl $(9 z, 12 z)-9,12$-octadecadienoate & 79.10 \\
\hline 31.633 & 587962 & 0.70 & 173840 & 0.70 & 9-Octadecenoic acid (z)-, ethyl ester & 55.05 \\
\hline 31.990 & 1535227 & 1.83 & 498854 & 2.01 & Octadecanoic acid, Ethyl ester & 88.10 \\
\hline 32.349 & 691102 & 0.82 & 206014 & 0.83 & Phytol, Acetate & 68.10 \\
\hline 33.872 & 645185 & 0.77 & 216792 & 0.87 & Heptacosane & 57.10 \\
\hline 35.431 & 617910 & 0.74 & 200934 & 0.81 & Ethyl nonadecanoate & 88.10 \\
\hline 37.081 & 1528344 & 1.82 & 461910 & 1.86 & 1-Octadecanol & 57.10 \\
\hline 37.178 & 2716157 & 3.24 & 827885 & 3.34 & Eicosane & 57.10 \\
\hline 40.247 & 4253016 & 5.07 & 1088943 & 4.39 & Tetracosylheptafluorobutyrate & 57.10 \\
\hline 43.952 & 4575755 & 5.46 & 841134 & 3.39 & 1-Heptacosanol & 57.10 \\
\hline
\end{tabular}

acid, butyl oct-3-yl ester (4.55\%), dibutyl phthalate $(20.72 \%)$, phthalic acid, 5-methylhex-2-yl butyl ester (9.01\%), hexadecanoic acid, ethyl ester (3.67\%), eicosane $(5.06 \%)$, phytol $(1.67 \%)$, dotriacontane $(0.95 \%)$, octadecanoic acid, methyl ester $(0.34 \%)$, 1-heneicosanol $(1.26 \%)$, heneicosane $(3.16 \%)$, tetrapentacontane $(0.59 \%)$, octadecane, 3-ethyl-5-(2-ethylbutyl)- (0.53\%), n-tetracosanol-1 (0.93\%), celidoniol, deoxy- $(2.07 \%)$ and 1,2-benzenedicarboxylic acid (7.77\%). The maximum number for tentative confirmation of chemical entities was identified in chloroform fraction while minimum probable chemical components were found in ethanolic extract.

\section{DISCUSSION}

In the current era, the enthusiasms toward the investigation of the herbal chemical entities and their actions have enlarged. The GC-MS is a powerful skill for qualitative and quantitative examination of bioactive constituents in a plant. Decent variety of plants and herbs holding different phytoconstituents with therapeutic spectrum can be operated as a promising remedial key. Distinctive phytochemicals have been found to have an expansive scope of activities, which may help in insur- ance for serious infections. ${ }^{19}$ The common chemical entities found in all three extracts/fractions (Ethanolic, n-hexane and chloroform) are phenol/phenol analogue $(6.93 \%$ in ethanolic, $5.69 \%$ i.e. 2,4-ditert-butylphenol in n-hexane and $8.68 \%$ in chloroform), phytol/phytol analogue $(3.27 \%$ in ethanolic, $16.15 \%$ in $n$-hexane and $1.67 \%$ in chloroform), neophytadiene $(0.94 \%$ in ethanolic, $5.25 \%$ in $\mathrm{n}$-hexane and $2.86 \%$ in chloroform), octadecane $(0.56 \%$ in ethanolic, $1.14 \%$ in $\mathrm{n}$-hexane and $0.53 \%$ in chloroform), hexahydrofarenesyl acetone $(1.11 \%$ in ethanolic, $7.80 \%$ in $n$-hexane and $2.74 \%$ in chloroform), methyl ester $(1.10 \%$ in ethanolic, $1.05 \%$ in $\mathrm{n}$-hexane and $0.34 \%$ in chloroform) and hexadecanoic acid $(19.48 \%$ in ethanolic, $13.71 \%$ in $\mathrm{n}$-hexane and $3.67 \%$ in chloroform). The GC-MS studies of promising ATWS extracts/fractions (Ethanolic, n-hexane and chloroform) revealed numerous chemical constituents which have many assets. The compound phytol which is indicated in GC-MS studies has known for its antimicrobial, anticancer, anti-inflammatory and cosmetics applications. ${ }^{20,21}$ Moreover, constituent 2,4-ditert-butylphenol has reported on antioxidant and antimicrobial properties while neophytadiene in excellent analgesic, antipyretic, anti-inflammatory, antimicrobial and anti- 


\section{Table 4: Chemical Entities Detected in ATWS Chloroform Fraction.}

\begin{tabular}{|c|c|c|c|c|c|c|}
\hline R. Time & Area & Area $\%$ & Height & Height $\%$ & Name & Base $\mathrm{m} / \mathrm{z}$ \\
\hline 17.034 & 11597563 & 8.68 & 2797907 & 7.02 & Phenol, 2,4-bis(1,1-dimethylethyl)- & 191.15 \\
\hline 19.188 & 2489368 & 1.86 & 773362 & 1.94 & Hexadecane & 57.10 \\
\hline 23.122 & 19919001 & 1.49 & 461252 & 1.16 & (-)-Loliolide & 11.10 \\
\hline 23.459 & 1541289 & 1.15 & 509796 & 1.28 & E-15-Heptadecenal & 55.05 \\
\hline 23.610 & 3979223 & 2.98 & 1422204 & 3.57 & Nonadecane & 57.05 \\
\hline 23.713 & 1259473 & 0.94 & 396501 & 0.99 & 3-Heptadecanol & 59.05 \\
\hline 24.080 & 496366 & 0.37 & 177876 & 0.45 & Isopropyl myristate & 60.00 \\
\hline 24.365 & 3824997 & 2.86 & 1325483 & 3.33 & Neophytadiene & 68.10 \\
\hline 24.471 & 3665626 & 2.74 & 1289674 & 3.24 & Hexahydrofarnesyl acetone & 58.05 \\
\hline 25.246 & 1557489 & 1.17 & 475247 & 1.19 & Phytol, Acetate & 82.05 \\
\hline 25.823 & 17511494 & 13.11 & 4827645 & 12.11 & $\begin{array}{c}\text { 1,2-Benzenedicarboxylic acid, Bis(2- } \\
\text { methylpropyl) ester }\end{array}$ & 149.05 \\
\hline 26.058 & 468030 & 0.35 & 125843 & 0.32 & Tetrapentacontane, 1,54-dibromo- & 57.10 \\
\hline 26.156 & 6078595 & 4.55 & 2030212 & 5.09 & Phthalic acid, Butyl oct-3-yl ester & 149.05 \\
\hline 26.798 & 27682239 & 20.72 & 7705748 & 19.33 & Dibutyl phthalate & 149.05 \\
\hline 27.131 & 12042290 & 9.01 & 3654688 & 9.17 & $\begin{array}{c}\text { Phthalic acid, 5-methylhex-2-yl butyl } \\
\text { ester }\end{array}$ & 149.05 \\
\hline 27.498 & 4904630 & 3.67 & 890482 & 2.23 & Hexadecanoic acid, Ethyl ester & 149.05 \\
\hline 27.650 & 6756050 & 5.06 & 1999901 & 5.02 & Eicosane & 57.10 \\
\hline 29.713 & 2227962 & 1.67 & 699717 & 1.76 & Phytol & 71.10 \\
\hline 29.910 & 1262927 & 0.95 & 457304 & 1.15 & Dotriacontane & 57.05 \\
\hline 30.000 & 453431 & 0.34 & 174634 & 0.44 & Octadecanoic acid, Methyl ester & 74.05 \\
\hline 31.232 & 1689121 & 1.26 & 605386 & 1.52 & 1-Heneicosanol & 57.05 \\
\hline 31.340 & 4224869 & 3.16 & 1620539 & 4.07 & Heneicosane & 57.10 \\
\hline 33.586 & 788103 & 0.59 & 311416 & 0.78 & Tetrapentacontane & 57.10 \\
\hline 33.895 & 706242 & 0.53 & 230962 & 0.58 & Octadecane, 3-Ethyl-5-(2-ethylbutyl)- & 57.05 \\
\hline 34.653 & 1238690 & 0.93 & 455164 & 1.14 & N-Tetracosanol-1 & 57.10 \\
\hline 34.740 & 2770215 & 2.07 & 1040339 & 2.61 & Celidoniol, Deoxy- & 57.05 \\
\hline 36.850 & 10375067 & 7.77 & 3399575 & 8.53 & 1,2-Benzenedicarboxylic acid & 149.05 \\
\hline
\end{tabular}

oxidant spectrum..$^{22-23}$ Previous studies on octadecane derivative showed the moderate inhibitory effect against bacterial strains. ${ }^{24}$ Another study of oil comprising of hexahydrofarnesyl acetone constituent has reported for its antimicrobial effect. ${ }^{25}$ The fatty acid (Methyl ester) reported for moderate antimicrobial activities. ${ }^{26}$ The leaves extracts showed varying marked antibacterial worth which might be owing to the supply of active phytoconstituents in the specific fraction of ATWS. The greater antibacterial activity might exhibit due to the presence of more than one active constituent soluble in a promising fraction. ${ }^{27}$ This may also act as a powerful tool to further assess their usage in food and non-food system.

\section{CONCLUSION}

In the present investigation, leaves part of varying extracts has revealed the significant antibacterial prospective against tested bacterial strains. The estimation of the level of bacterial resistance to antibiotics serves as a vital precursor for management of infectious diseases. Thus, kinetic studies for evaluation of antibiotic susceptibility have presented numerous merits such as predicting concentration accurately, long antibiotic exposure examinations etc. ${ }^{28}$ In order to further understand the chemical nature guided for these activities, it may act as a better understanding tool to explore further these results. 


\section{ACKNOWLEDGEMENT}

The authors gratefully acknowledge the funding agency UGC, New Delhi, India for their financial support in the form UGC-BSR fellowship (F.7-36/2007). Authors are thankful to KFRI-Kerala Forest Research Institute, India for affording GC-MS facility during the study. The authors are too appreciative to BIT Mesra (India), for providing compulsory facilities for this project.

\section{CONFLICT OF INTEREST}

The authors declare no conflict of interst.

\section{ABBREVIATIONS}

ATWS: Arisaema tortuosum (Wall.) Schott; Sa: Staphylococcus aureus; Bs: Bacillus subtilis; Ec: Escherichia coli; St: Salmonella typhimurium; MIC: Minimum Inhibitory Concentration; ZOI: Zone of Inhibition; GC-MS: gas chromatography-mass spectrmetry; MH: Mueller-Hinton; MHA: Mueller-Hinton Agar.

\section{REFERENCES}

1. Winstanley TG, Limb DI, Eggington R, Hancock F. A 10-year survey of the antimicrobial susceptibility of urinary tract isolates in the UK: The Microbe Base project. J Antimicrob Chemother. 1997;40(4):591-4.

2. Agrawal P, Rai V, Singh RB. Randomized placebo-controlled, single blind trial of holy basil leaves in patients with noninsulin-dependent diabetes mellitus. Int J Clin Pharmacol Ther. 1996;34(9):406-9.

3. Kiruthika KA, Jaisheeba A, Sornaraj R. Evaluation of antibacterial activity of some selected Angiosperm flower extract. Int J Chemtech Res. 2011;3(4):1945-51.

4. Pragada PM, Rao DS, Venkaiah M. Study of some ethnomedicinal plants for treatment of dysentery of North Coastal Andhra Pradesh, India. Int J Biosci. 2012;2(1):18-24.

5. Choudhary K, Singh M, Pillai U. Ethnobotanical survey of Rajasthan-An update. Am Eurasian J Bot. 2008;1(2):38-45.

6. Sharma PP, Majumdar AM. Traditional knowledge of plants from Toranmal Plateau of Maharashtra. IJTK. 2003;2(3):292-6.

7. Verma H, Lal V, Pant K, Soni N. A Ethno medicinal Review on Arisaema tortuosum. Int J Adv Pharm Biol Chem. 2012;1(2):176-9.

8. Milgani BD, Cxhawla AS, Singh A, Gaind KN. Chemical investigation of Arisaema tortuosum corm. IJP. 1978;40(1):24-5.

9. Nile SH, Park SW. HPTLC analysis, antioxidant, anti-inflammatory and antiproliferative activities of Arisaema tortuosum tuber extract. Pharm Biol. 2014;52(2):221-7.
10. Dhuna V, Bains JS, Kamboj SS, Singh J, Saxena AK. Purification and characterization of a lectin from Arisaema tortuosum Schott having in-vitro anticancer activity against human cancer cell lines. J Biochem Mol Biol. 2005;38(5):526-32.

11. Iordache F, lonita M, Mitrea LI, Fafaneata C, Pop A. Antimicrobial and antiparasitic activity of lectins. Curr Pharm Biotechnol. 2015;16(2):152-61.

12. Kant K, Lal UR, Ghosh M. In silico prediction and wet lab validation of Arisaema tortuosum (Wall.) schott extracts as antioxidant and anti-breast cancer source: A comparative study. Pharmacogn Mag. 2017;13(52):786-90.

13. Rojas JJ, Ochoa VJ, Ocampo SA, Muñoz JF. Screening for antimicrobial activity of ten medicinal plants used in Colombian folkloric medicine: A possible alternative in the treatment of non-nosocomial infections. BMC Complement Altern Med. 2006;6(1):2.

14. Wong MH, Lim LF, Ahmad BF, Assim BZ. Antioxidant and antimicrobial properties of Litseaelliptica Blume and Litsearesinosa Blume (Lauraceae). Asian Pac J Trop Biomed. 2014;4(5):386-92.

15. Sarker SD, Nahar L, Kumarasamy Y. Microtitre plate-based antibacterial assay incorporating resazurin as an indicator of cell growth and its application in the in vitro antibacterial screening of phytochemicals. Methods. 2007;42(4):321-4.

16. Kumar VD, Verma PR, Singh SK. Morphological and in vitro antibacterial efficacy of quercetin loaded nanoparticles against food-borne microorganisms. LWT-Food Sci Technol. 2016;66:638-50.

17. Abirami P, Rajendran A. GC-MS analysis of methanol extracts of Vernoniacinerea. Euro J Exp Biol. 2012;2(1):9-12.

18. Prajapati R, Roy S, Mishra S, Raza SK, Thakur LK. Formulation development, standardization and antimicrobial activity of Ageratum conyzoides extracts and their formulation. Int J Pharm Pharm Sci. 2014;6(2):369-74.

19. Liu RH. Health benefits of fruits and vegetables are from additive and synergic combinations of phytochemicals. Am J Clin Nutr. 2003;78(3):517-20.

20. Grover N, Patni V. Phytochemical characterization using various solvent extracts and GC-MS analysis of methanolic extract of Woodfordiafruticosa kurz. Int J Pharm Pharm Sci. 2013;5(4):291-5.

21. Ginty MD, Letizia CS, Api AM. Fragrance material review on phytol. Food Chem Toxicol. 2010;48(3):59-63.

22. Varsha KK, Devendra L, Shilpa G, Priya S, Pandey A, Nampoothiri KM. 2, 4-Di-tert-butyl phenol as the antifungal, antioxidant bioactive purified from a newly isolated Lactococcus sp. Int J Food Microbiol. 2015;211:44-50.

23. Raman BV, La S, Saradhi MP, Rao BN, Khrisna AN, Sudhakar M, et al. Antibacterial, antioxidant activity and GC-MS analysis of Eupatorium odoratum. Asian J Pharm Clin Res. 2012;5(2):99-106.

24. Nguyen HT, Ho DV, Vo HQ, Le AT, Nguyen HM, Kodama T, et al. Antibacterial activities of chemical constituents from the aerial parts of Hedyotispilulifera. Pharm Biol. 2017;55(1):787-91.

25. Radulović N, Stojanović G, Palić R. Composition and antimicrobial activity of Equisetum arvense L. essential oil. Phytother Res. 2006;20(1):85-8.

26. Chandrasekaran M, Kannathasan K, Venkatesalu V. Antimicrobial activity of fatty acid methyl esters of some members of Chenopodiaceae. Z Naturforsch C. 2008;63(5-6):331-6.

27. Bibi Y, Nisa S, Chaudhary FM, Zia M. Antibacterial activity of some selected medicinal plants of Pakistan. BMC Complement Altern Med. 2011;11(1):52.

28. Theophel K, Schacht VJ, Schlüter M, Schnell S, Stingu CS, Schaumann $\mathrm{R}$, et al. The importance of growth kinetic analysis in determining bacterial susceptibility against antibiotics and silver nanoparticles. Front Microbiol. 2014;5:544.

Cite this article: Kant K, Lal UR, Ghosh M. Antibacterial Activity with Bacterial Growth Kinetics and GC-MS Studies on Leaf and Tuber Extracts of Arisaema tortuosum (Wall.) Schott. Indian $\mathrm{J}$ of Pharmaceutical Education and Research. 2019;53(3 Suppl 2):s280-s287. 


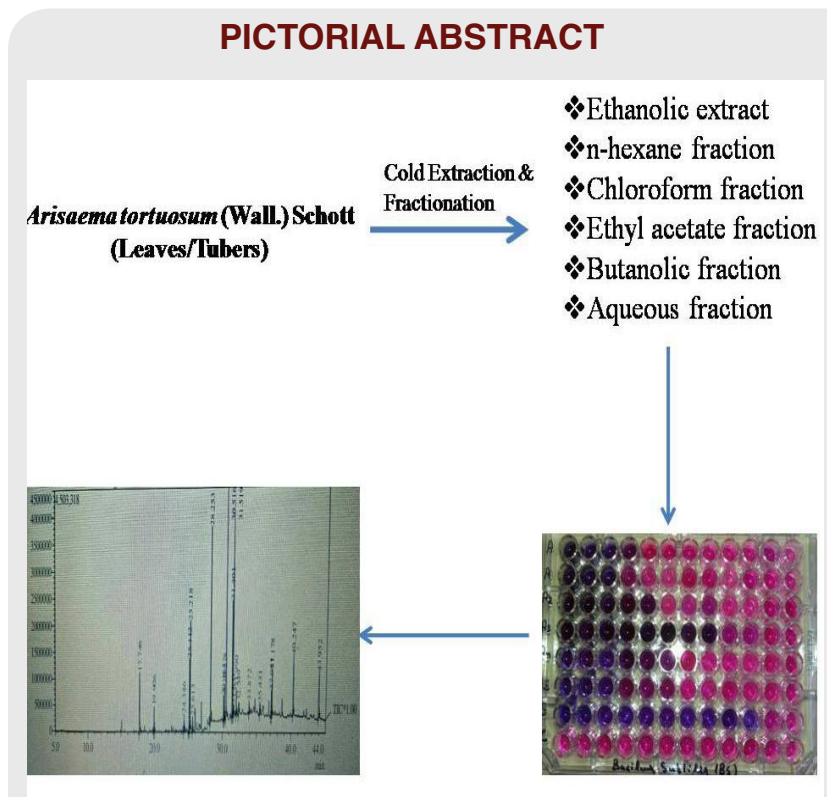

ABOUT AUTHORS

\section{SUMMARY}

- Arisaema tortuosum (Wall.) Schott (ATWS), commonly known as whipcord cobra lily (family: Araceae) has great therapeutic applications.

- Very few studies have been documented on ATWS (tubers) such as antioxidant, anti-inflammatory, antimicrobialand anticancer properties.

- Our objectives were to explore limited studies as evaluation of the ATWS different extracts and their fractions (leaves and tubers) for antibacterial activity and to tentatively analyze the components present in promising extracts using Gas Chromatography-Mass Spectroscopy (GC-MS).

- Overall, leaf extract and its fractions showed remarkable activity and kinetic pattern against Staphylococcus aureus, Bacillus subtilis, Escherichia coli and Salmonella typhimurium.

- Numerous tentative compounds were qualitativelyindicated in promising antibacterial extracts using GC-MS.

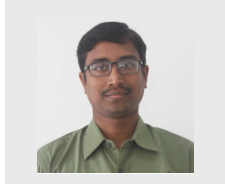

Manik Ghosh: He had his Ph.D from Department of Pharmaceutical Sciences and Technology, Birla Institute of Technology, Mesra, Ranchi. Currently, he is working as an Assistant Professor at the Department of Pharmaceutical Science and Technology, BIT Mesra. He is actively involved in the following research fields: Isolation and Characterization of biological active compounds (antiviral / anticancer) from natural sources; Analytical and Bio-analytical chemistry; in silico Drug Designing. His research activity is proved by numerous noteworthy publications on international journals

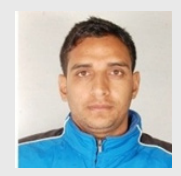

Kamal Kant is currently a Senior Research Fellow pursuing Ph.D from Department of Pharmaceutical Sciences and Technology, Birla Institute of Technology, Mesra, Ranchi. He achieved his M. Pharmacy (Pharmaceutical Chemistry) in 2012 from Kumaun University, Bhimtal campus. He has published in various reputed national and international conferences and journals. Notably, he has been adjudged as the best paper in the field of Pharmacognosy, Phytochemistry and Alternate Medicine and Pharmaceutical Biotechnology to receive the Prof. M.L. Khorana Memorial Prize for the year 2013. His area of interest comprises Phytochemistry, Analytical chemistry and in silico Drug Designing.

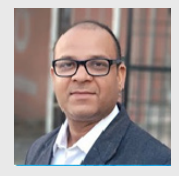

Uma Ranjan Lal: He has obtained his Ph.D from National Institute of Pharmaceutical Education and Research, S.A.S. Nagar, Mohali in 2010. He has more than ten years of teaching and sixteen years of research experience. He has various national and international publications in form of a monograph series book book chapters, and research and review articles. His key areas of cancer research involve isolation and characterization of novel molecules from plant sources, Anti-cancer drug loaded novel drug delivery systems, herbal formulations and nutraceuticals in cancer research. 